Aim of the study: Despite the increase in studies concerning oncoplastic reduction mammoplasty (ORM), data showing long-term aesthetic and patient satisfaction for ORM in patients with macromastia remain limited. Therefore, this study evaluated the long-term results of tumorectomy and concomitant bilateral ORM for earlystage breast cancer patients with macromastia in terms of cosmesis, patient satisfaction, and functional outcomes. Material and methods: Retrospective data of patients with macromastia undergoing ORM for breast cancer between 1996 and 2011 were examined and evaluated regarding the aesthetic results, patient satisfaction, and functional outcomes.

Results: The median age of the 82 patients was 50 years. The median follow-up was 120 months (range: 28-212 months). The median breast volume was $1402 \mathrm{~cm}^{3}$, and the median weight of the excised breast material was $679 \mathrm{~g}$. A good or excellent evaluation of the cosmetic outcome was as follows: self-evaluation: $84.1 \%$ at the early-stage, $80.3 \%$ at the later stage; panel evaluation: $75.4 \%$ at the late-stage. Median patient satisfaction rates were $9.1 \%$ for early-stage disease and $8.8 \%$ for late-stage disease. Reduced mobility and intertrigo improved by three-fold during the post-operative period.

Conclusions: ORM for early-stage breast cancer in women with macromastia results in good cosmesis in both the early-stage and long-term, and is quite acceptable for use in patients. Patients reacted favorably to the prospect of having their breast cancer and macromastia treated in a single session, and positive results continued over the long-term.

Key words: breast cancer, macromastia, oncoplastic reduction mammoplasty, cosmesis, satisfaction.

Contemp Oncol (Pozn) 2016; 20 (3): 256-260 DOI: $10.5114 /$ wo.2015.55272

\section{Oncoplastic reduction mammoplasty for breast cancer in women with macromastia: long term aesthetic, functional and satisfaction outcomes}

Mustafa Emiroglu, Cem Karaali, Semra Salimoglu, Ismail Sert, Cengiz Aydın

Department of General Surgery, Tepecik Training and Research Hospital, Izmir, Turkey

\section{Introduction}

Breast-conserving surgery (BCS), the standard treatment for early-stage breast cancer, generates certain cosmetic and functional problems. These include a large breast size and problems associated with radiotherapy (RT), cosmesis, and patient satisfaction. The frequency of macromastia in breast cancer patients undergoing BCS is reported to be $40 \%$ [1]. In Losken's meta-analysis, the satisfaction rate of post-BCS is reported to be $83 \%$ [2]. Some problems have been reported with RT dose homogeneity in post-BCS patients with large breasts [3], and aesthetic concerns in post-BCS patients have reached $30 \%$ [4]. Indeed, post-operative RT problems, aesthetic concerns, and overall patient satisfaction rate are considered relative contraindications for the choice of BCS in breast cancer cases with macromastia.

Bilateral oncoplastic reduction mammoplasty (ORM) combines the techniques of tumorectomy and bilateral breast reduction. With this method, the tumor can be excised with wider margins, and the effectiveness of RT on a reduced breast is increased [5]. The aesthetic concerns that occur with BCS are reduced to $7 \%$ with the ORM procedure [6]. In addition, with ORM, a significant amount of breast parenchyma is removed from both the ipsilateral and contralateral breasts. It is believed that in ancient times, Amazon women had their right breasts removed to facilitate their social functions [7]. Currently, because screening programs and adjuvant therapies indicate that breast cancer patients have a longer life expectancy, breast aesthetics and quality of life have become more critical. Macromastia can cause dysfunctional problems such as back, neck, and shoulder pain, recurrent intertrigo, and a decline in physical activity, all of which diminish the quality of life [8]. Bilateral reduction mammoplasty improves the quality of life [9]. It has been shown that concomitant ORM leads to greater patient satisfaction and a better quality of life than when it is performed in later stages [10]. Recently, despite the increase in ORM studies, we have been unable to find data showing long-term aesthetic, functional, and patient satisfaction for ORM in patients with macromastia, although this is by far the more common procedure. Therefore, the primary endpoint of this study was to evaluate the aesthetic results and satisfaction rates for a 10-year period in patients with early-stage breast cancer and macromastia. The secondary endpoint was to assess the functional outcomes in that group.

\section{Material and methods}

A retrospective review of the medical records of consecutive patients with breast cancer and macromastia undergoing concomitant ORM between January 1996 and May 2011 at Tepecik Training and Research Gen- 
eral Hospital was performed. Both the files and data recorded on the hospital's Probel system were examined. According to the 2010 AJCC-UICC (American Joint Cancer Committee- Union Internationale Centre-le-Cancer) breast cancer staging system, stages I and II were included in the present study. Patients with in situ, stage III breast cancer or a breast volume $<1000 \mathrm{~cm}^{3}$ were not included. Eight patients who underwent ORM withdrew from observation and were removed from the study. All of the cases were first discussed and planned in multidisciplinary weekly meetings. After the risks and benefits of the technique had been discussed at length with the patient group, the procedure was performed on those providing authorization. Informed written consent was obtained for both the surgical procedure and for inclusion in the current study.

Macromastia was defined as a breast volume $>1000 \mathrm{~cm}^{3}$. Eighty-two consecutive patients were admitted to the study. The cases were examined for demographics, macromastia, operative and oncologic outcomes, complication factors, adjuvant therapy, cosmetic outcomes, and patient satisfaction. The oncological outcomes of this study are the subject of another study.

\section{Patient evaluation and operative techniques}

Based on the unit protocol, routine pre-operative oncological screening was performed in all of the patients diagnosed with breast cancer. The breast volume of all of the patients was measured using a Grousman-Roudner Device (GRD) [11]. Breast asymmetry was accepted as a disparity in breast volume greater than $10 \%$. During the pre-operative evaluation, we determined the tumor quadrant to be excised, choice of nipple areola complex (NAC) flap, access to the axilla, choice of skin incision, and estimated volume of the breast tissue to be removed. Similar decisions were made for the contralateral breast. Tumors were to be excised by oncological principals macroscopically using a minimum margin of $1.5 \mathrm{~cm}$. Intraoperative margin control was achieved using frozen sections and specimen mammography, and any re-excision was performed immediately. The only skin removed, comprised biopsy incision scars and the skin covering tumors close to the surface. Nipple resection was performed in tumors closer than $2 \mathrm{~cm}$ to the nipple. Similar procedures were simultaneously performed on the contralateral breast for symmetry. The ipsilateral breast was left 10\% larger to allow for shrinkage during RT. At least two members of the five-strong surgical team were present at each operation. For axiller surgery before ORM, intraoperative sentinel lenf node biyopsy was applied in fifty cases.

In most cases, the Wise pattern incision [12] was chosen for its ease of axillary access, flap alternatives, and ease of breast reconstruction. We preferred the vertical incision in cases of macromastia $<1300 \mathrm{~cm}^{3}$ to minimize the incision. Our choice of NAC-carrying pedicle was based on forming a pedicle in the breast section furthest from the tumor. A free nipple graft was used in cases where the NAC distance was greater than $35 \mathrm{~cm}$. In cases of nipple involvement, we performed central resection, followed by a Grisotti flap procedure. Next, axillary surgery was per- formed. Complications were considered to be either early ( $<2$ months) or late ( $>2$ months).

Standard RT was applied 3 weeks post-operatively with 50 Gy to the whole breast and a boost to the tumor bed of 10 Gy. Thirty two patients had radiotherapy by using cobalt and others by linear accelerator. Twenty-four cases were administered chemotherapy (CT). CT and hormone therapy $(\mathrm{HT})$ were applied in 25 cases, and $\mathrm{HT}$ alone was used in 35 cases. In addition, 16 c-erb-B2 cases were treated with trastuzumab.

In the post-operative period, patients were seen by surgeons and/or medical oncologists for physical and radiological follow-up. All of the patient data were recorded.

\section{Cosmetic outcomes and patient satisfaction}

Esthetic and satisfaction assesment were done in survivals and who accepted to take photographs and who only underwent to oncoplastic reduction. For the purposes of this study, self-evaluation by patients of cosmetic outcomes and satisfaction were considered early-stage at $<6$ months post-operatively and late-stage at $>2$ years post-operatively. The cosmetic outcome was rated on a scale of 1-4 (4 - excellent, 3 -good, 2 - moderate, 1 - poor). Early-stage aesthetic evaluation was completed by a member of the surgical team and by the patient herself. Late-stage evaluation was carried out by the patient, and by a panel comprising two team surgeons, one plastic surgeon, one surgery nurse, and a non-medical layperson. Anonymized photographs taken from the front, right, and left at 45-degree angles were used in the panel evaluations. The shape and size of the breast, state of the skin and scar, symmetry, and NAC location were all scored on a scale of $1-4$. These points were computed to form the panel aesthetic score (20-16 - excellent; 15-11-good; 10-6 - moderate; $5-1$ - poor). The Likert scale (1-10) was used for patient self-evaluation of early-stage and late-stage aesthetic and functional outcomes, as well as overall satisfaction.

\section{Macromastia}

Functional result assesment of macromasty was done for survivals and who accepted to measure the volume of the breast. For this purpose the measurement of breast volumes and symptoms related to macromastia were obtained during the pre-operative period and patients' last control.

\section{Statistics}

Data were analyzed using SPSS version 15 (SPSS Inc., Chicago, IL, USA). Chi-squared analysis was performed for the comparison of the cosmetic results and symptoms of patients with macromastia (pre-operative and last evaluation). Evaluation of early and late satisfaction, as well as cosmetic evaluation, was accomplished using repeated-measures tests. The effect sizes were calculated for each evaluated group. Effect sizes up to 0.2 were considered small; effect sizes of approximately 0.5 were considered moderate; effect sizes of approximately 0.8 were considered large. The patient and treatment groups were compared using the log-rank test. Multivariate analyses 
Table 1. Evaluation of the cosmesis and satisfaction

\begin{tabular}{|c|c|c|c|}
\hline Evaluation & Early, $n$ (\%) & Late, $n(\%)$ & $\begin{array}{l}P \text {-value/ } \\
\text { effect size }\end{array}$ \\
\hline Number of patients & 82 & 61 & - \\
\hline \multicolumn{4}{|c|}{ Cosmetic evaluation by the surgeon } \\
\hline Excellent & $26(31.7)$ & - & - \\
\hline Good & $38(46.3)$ & - & - \\
\hline Moderate & 14 (17.1) & - & - \\
\hline Poor & $4(4.9)$ & - & - \\
\hline \multicolumn{4}{|c|}{ Cosmetic evaluation by the patient } \\
\hline Excellent (4) & $26(31.7)$ & $18(29.5)$ & - \\
\hline Good (3) & $43(52.4)$ & $31(50.8)$ & - \\
\hline Moderate (2) & $12(14.6)$ & 8 (13.1) & - \\
\hline Poor (1) & $1(1.2)$ & $4(6.6)$ & - \\
\hline $\begin{array}{l}\text { Patient score } \\
(\text { mean } \pm S D)\end{array}$ & $3.15 \pm 0.67$ & $3.0 \pm 0.80$ & $0.08 / 0.88$ \\
\hline \multicolumn{4}{|c|}{ Cosmetic evaluation by the panel } \\
\hline $\begin{array}{l}\text { Excellent } \\
\text { Good } \\
\text { Moderate } \\
\text { Poor }\end{array}$ & $\begin{array}{l}- \\
- \\
- \\
-\end{array}$ & $\begin{array}{c}15(24.6) \\
31(50.8) \\
12(19.7) \\
3(4.9)\end{array}$ & $\begin{array}{l}- \\
- \\
- \\
-\end{array}$ \\
\hline \multicolumn{4}{|l|}{ Patients' satisfaction } \\
\hline $9-10$ & $65(79.3)$ & $46(75.4)$ & - \\
\hline $7-8$ & $13(15.9)$ & $7(11.5)$ & - \\
\hline $5-6$ & $3(3.7)$ & $6(9.8)$ & - \\
\hline $3-4$ & $1(1.2)$ & $2(3.3)$ & - \\
\hline $1-2$ & 0 & 0 & - \\
\hline $\begin{array}{l}\text { Satisfaction score } \\
(\text { mean } \pm \text { SD) }\end{array}$ & $9.1 \pm 1.37$ & $8.8 \pm 1.59$ & $0.03 / 0.11$ \\
\hline
\end{tabular}

were performed using Cox proportional hazard models to test the differences between groups. In the analyses, $p$-values less than 0.05 indicated statistical significance.

\section{Results}

\section{Patient data}

The median follow-up was 121 months (range: 28-212 months). The median age was 49 years (range: $31-70)$. The median body mass index (BMI) was 28.9 (range: 22-43). At the time of diagnosis, 65 patients (79.3\%) were post-menopausal. The median length of post-operative hospital stay was 3.4 days (range: 2-13 days), and the tumor was on the right side in 42 patients (53.6\%).

\section{Operative findings}

The mean length of operation was $124 \pm 25$ min (range: 80-190 min). Quadrantectomy followed by oncoplastic reduction was performed in the first 27 cases. In the subsequent 55 cases, the tumor area was excised en bloc. For the skin incision, the Wise pattern was implemented in 60 cases, and a vertical incision was implemented in 22 cases. Most of the tumors were located in the upper outer quadrant $(n=25)$. For reconstruction, 48 inferior, 17 superior medial, 7 superior, 4 free nipple, 4 superior lat- eral, and 3 Grisotti flaps were employed. Similar techniques were used concomitantly for the contralateral breast.

\section{Histopathological evaluation and oncology}

The median tumor size was $26 \mathrm{~mm}$ (range: 4-47 mm). The number of patients in stages 1 and 2 were 36 and 46, respectively. Patients with ductal and lobular carcinoma were 75 and 7 , respectively. The number of patients who were receptor-positive was 56. In 16 patients, Her2 b was positive. Positive margins were found in three cases (3.7\%) and a close margin was found in one case. Re-excision was performed for these cases. During the follow-up, local excision was performed in three cases of breast recurrence and one case of axillar recurrence. One patient underwent a mastectomy and transverse rectus abdominis myocutaneous (TRAM) reconstruction due to tumor recurrence in the breast.

\section{Complications}

Ten (12.2\%) cases showed early complications: suture-line dehiscence $(n=4)$, seroma $(n=3)$, wound site infection $(n=2)$ and areola necrosis $(n=1)$. Adjuvant treatment was postponed by 10-20 days (after 3 weeks post-operatively) in the four (4.9\%) cases of incision opening and areola necrosis. Late complications were observed in 12 (14.6\%) cases: skin problems (color, scarring), fat necrosis and fibrosis (re-excision was performed), impaired breast shape (dog ear correction), breast hypertrophy (treated with re-reduction), and chronic mastalgia.

\section{Cosmesis and patient satisfaction}

The final cosmetic and patient satisfaction evaluation was based on 61 patients, because 14 patients died, 6 patients refused to be photographed, and 1 patient underwent the TRAM flap procedure. Table 1 shows the details. There was a decrease in self-evaluation scores for cosmetic outcomes ( $p=0.08$; effect size: 0.11 ), and a smaller decrease in patient satisfaction with the ORM procedure ( $p=0.03$; effect size: 0.11 ) over the long-term.

\section{Macromastia}

The median weight of breast tissue removed was $678 \mathrm{~g}$ (range: 330-1300 g), with $671 \mathrm{~g}$ (range: 350-1180 g) from the right tissue and $685 \mathrm{~g}$ (range: 330-1300 g) from the left tissue. Because 4 patients died and 3 patients refused breast volume measurement, the final breast volume evaluation was based on a total of 65 patients. Table 2 summarizes the data for macromastia and its symptoms. Reduced mobility and intertrigo improved by three-fold during the post-operative period.

\section{Discussion}

The main finding of this original study is that the choice of concomitant ORM BCS led to improved aesthetic and functional outcomes for women with early-stage breast cancer and macromastia according to the long-term results. This procedure was viewed favorably by a large proportion of the patient cohort. 


\section{Aesthetics and satisfaction}

Cosmetically favorable results have been achieved with this combination of breast procedures. Cordosa et al. [13] suggested that cosmetic evaluation after BCS should be performed before RT, and then in the $1^{\text {st }}, 5^{\text {th }}$, and $10^{\text {th }}$ years post-operatively. The inclusion of subjective evaluations, such as patient self-evaluation and panel evaluation, is also recommended. In breast cancer patients with macromastia treated with ORM, a cosmetic evaluation of good or excellent, using invalidated methods, was between $57 \%$ and $93 \%$ (Table 3). In a systematic review, which was recommended to be performed after at least 2 years post-operatively, the rate of OMC was $84-89 \%$ [19]. The median rate reported in Losken's meta-analysis for women undergoing BCS was 80\% [2]. Hernanz [20] reported that ORM significantly improved the quality of life in cancer patients with macromastia. Grey [21] mentioned that RT causes greater retraction in heavy women with large-sized breasts, and that there is a drop in the 5-year aesthetic results. In our study, in both early-stage and late-stage patient cosmesis evaluations, good or excellent results were achieved in almost four-fifths of the cases. Similar to the results reported in the literature, the results of the present study decreased over time. The most important factor in cosmesis is breast symmetry. Despite pre-operative asymmetry and post-operative RT, our study established that late-stage disease was associated with improved symmetry using the objective criteria of breast volume measurement. In addition, during intraoperative breast volume calibration, leaving approximately $10 \%$ more tissue on the side that would receive RT helped to reduce asymmetry. One benefit of using ORM with these patients is that such adjustments can easily be made.

Our study showed that, in this group of patients undergoing ORM, a very high patient satisfaction rate was achieved in both the short-term and long-term. Invalidated methods were mostly used for measuring patient satisfaction. Newman and Munhoz [14, 16] published satisfaction rates of $93 \%$ and $86 \%$ for very satisfied and satisfied patients, respectively. However, these studies did not include data for long-term satisfaction. Patient satisfaction may be affected by post-operative complications, breast asymmetry, and the passing of time. We believe that, despite the long follow-up time and complications, our good satisfaction rates are due to the improvement in macromastia symptoms and breast symmetry. It is likely that this patient satisfaction level was not based entirely on cosmetic results, but rather, reflects general satisfac-
Table 2. Characteristics of the patients with macromastia

\begin{tabular}{|c|c|c|c|}
\hline Characteristics & Pre-operative & Final evaluation & $P$-value \\
\hline $\begin{array}{l}\text { Number of the } \\
\text { patients }(n)\end{array}$ & 82 & 65 & \\
\hline Median BMI & $28.9(22-36)$ & $32.1(24-41)$ & - \\
\hline \multicolumn{4}{|c|}{ Median Breast volume $\left(\mathrm{cm}^{3}\right)$} \\
\hline Right breast & $\begin{array}{c}1380 \\
(100-1900)\end{array}$ & $\begin{array}{c}890 \\
(650-960)\end{array}$ & - \\
\hline Left breast & $1420(1050-200)$ & $875(67-940)$ & - \\
\hline \multicolumn{4}{|c|}{ Median distance of NAC (cm) } \\
\hline Right & $28.2(25-36)$ & $26.2(23-30)$ & - \\
\hline Left & $28.9(24-36)$ & $26.1(24-29)$ & - \\
\hline Asymmetry (\%) & $14(17.1)$ & $6(9.2)$ & 0.04 \\
\hline \multicolumn{4}{|l|}{ Symptoms (\%) } \\
\hline Backache & $68(83)$ & $26(40)$ & 0.02 \\
\hline Shoulder pain & $64(78)$ & $26(40)$ & 0.03 \\
\hline Neck pain & $55(67)$ & $20(31)$ & 0.03 \\
\hline \multicolumn{4}{|l|}{ Limitation } \\
\hline of movement & $51(62)$ & $12(19)$ & 0.04 \\
\hline Mastalgia & $38(46)$ & $20(31)$ & 0.02 \\
\hline Intertrigo & $31(38)$ & $8(12)$ & 0.01 \\
\hline
\end{tabular}

$B M I$ - body mass index; NAC - nipple areola complex

tion with the whole procedure. The high level of patient satisfaction was preserved over a long period of time. The cause may be that patients were grateful to be freed from the difficulties associated with macromastia.

\section{Macromastia}

In our study, we observed that ORM significantly decreased macromastia problems. For women with macromastia, quality of life and functional problems are as important as cosmetic anxiety. Chadbourne [8] noted that macromastia problems were resolved by reduction mammoplasty in more than half of the cases. The effective role of breast reduction in resolving macromastia symptoms, particularly those related to pain, is well documented [22]. In our study, we noted improvement in more than half of the macromastia symptoms in two-thirds of our cases; in particular, reduced mobility and intertrigo improved. In breast cancer patients with macromastia, two important problems can be addressed in one session with a synergistic effect. This is the most attractive aspect of the procedure, because ORM surgery allows for the ease of wide

Table 3. The studies on ORM in patients with macromastia

\begin{tabular}{|c|c|c|c|c|c|c|}
\hline & $n$ & Follow up (month) & Stage $T / m m$ & Specimen, g & Complication (\%) & Cosmesis (\%) \\
\hline Newman et al. [14] & 28 & 24 & 15 & 766 & 35.7 & 86 \\
\hline Chang et al. [15] & 37 & - & I, II & 653 & 16.2 & 70 \\
\hline Munhoz et al. [16] & 74 & 22 & - & 610 & 32.4 & 93 \\
\hline Kronowitz et al. [17] & 41 & 36 & - & 626 & 34.1 & 57 \\
\hline Currie et al. [18] & 20 & 34 & ।, II & 370 & 25 & 0 \\
\hline This study & 82 & 120 & I, II & 679 & 26.6 & 84 \\
\hline
\end{tabular}


excision of the tumor, while providing a solution to the patient's chronic problem. Furthermore, concomitant reconstructive surgery is reportedly $62 \%$ cheaper than two stand-alone surgeries [23].

\section{Limitations}

This study had some limitations. We may have influenced our patients in favor of ORM, and the aesthetic evaluations were done with invalidated methods. The effect of adjuvant treatment methods changed by the time on the aesthetic results was snoozed at in present study.

In conclusion, oncoplastic reduction mammoplasty for early-stage breast cancer in women with macromastia produces good cosmesis in both the short-term and long-term that are quite acceptable to the patients. The patients reacted favorably to the prospect of having their breast cancer and macromastia treated in a single session, and the positive results continued over the long-term. This technique widely diminishes the macromastia symptoms. We recommend further prospective, randomized trials for long-term and validated aesthetic results of ORM.

\section{The authors declare no conflict of interest.}

\section{References}

1. Dundas KL, Atyeo J, Cox J. What is a large breast? Measuring and categorizing breast size for tangential breast radiation therapy. Australas Radiol 2007; 51: 589-93.

2. Losken A, Dugal CS, Styblo TM, Carlson. A Meta-analysis comparing breast conservation therapy alone to the oncoplastic technique. Ann Plast Surg 2014; 72: 145-9.

3. Moody AM, Mayles WP, Bliss JM, A'Hern RP, Owen JR, Regan J, Broad B, Yarnold JR. The influence of breast size on late radiation effects and association with radiotherapy dose in homogeneity. Radiother Oncol 1994; 33: 106-12.

4. Clough KB, Cuminet J, Fitoussi A, Nos C, Mosseri V. Cosmetic sequelae after conservative treatment for breast cancer: classification and results of surgical correction. Ann Plast Surg 1998; 41: 471-81.

5. Kaur N, Petit JY, Rietjens M, Maffini F, Luini A, Gatti G, Rey PC, Urban C, De Lorenzi F. Comparative study of surgical margins in oncoplastic surgery and quadrantectomy in breast cancer. Ann Surg Oncol 2005; 12: 539-45.

6. Munhoz AM, Montag E, Arruda E, Pelarin L, Filassi JR, Piato JR, et al. Assessment of immediate conservative breast surgery reconstruction: a classification system of defects revisited and an algorithm for selecting the appropriate technique. Plast Reconstr Surg 2008; 121: 716-27.

7. Karacalar A The Amazons and an analysis of breast mutilation from a plastic surgeon's perspective. Plast Reconstr Surg 2007; 119: 810-8.

8. Chadbourn EB, Zhang SH, Gordon MJ. Clinical outcomes in redüction mammaplasty: A systemic review and meta-analysis of published studies. Mayo Clinic Proceedings 2001; 76: 503-10.

9. Blomqvist L, Eriksson A, Brandberg Y. Reduction mammaplasty provides long-term improvement in health status and quality of life. Plast Reconstr Surg 2000; 106: 991-7.

10. Patel KM, Hannan CM, Gatti ME, Nahabedian MY. A head-to-head comparison of quality of life and aesthetic outcomes following immediate, staged-immediate, and delayed oncoplastic reduction mammaplasty. Plast Reconstr Surg 2011; 127: 2167-75.

11. Kayar R, Civelek S, Cobanoglu M, Gungor O, Catal H, Emiroglu M. Five methods of breast volume measurement: a comparative study of measurements of specimen volume in 30 mastectomy cases. Breast Cancer (Auckl) 2011; 5: 43-52.

12. Rohrich RJ,Gosmann AA, Brown SA, Perish J. Mastopexy preferences: A survey of board-certified plastic surgeons. Plast Reconst Surg 2006;118: 1631-38.

13. Cardoso MJ, Cardoso JS, Vrieling C, Macmillan D, Rainsbury D, Heil J, Hau E, Keshtgar M. Recommendations for the aesthetic evaluation of breast cancer conservative treatment. Breast Cancer Res Treat 2012; 135: 629-37.

14. Newman LA, Kuerer HM, McNeese MD, Hunt KK, Gurtner GC, Vlas tos GS, Robb G, Singletary SE. Reduction mammoplasty improves breast conservation therapy in patients with macromastia. Am J Surg 2001; 181: 215-20.

15. Chang E, Johnson N, Webber B, Booth J, Rahhal D, Gannett D, Johnson W, Franzini D, Zegzula $\mathrm{H}$. Bilateral reduction mammoplasty in combination with lumpectomy for treatment of breast cancer in patients with macromastia. Am J Surg 2004; 187: 647-50.

16. Munhoz AM, Montag E, Arruda EG, Aldrighi C, Gemperli R, Aldrighi JM, Ferreira MC. Critical analysis of reduction mammaplasty techniques in combination with conservative breast surgery for early breast cancer treatment. Plast Reconstr Surg 2006; 117: 1091-103.

17. Kronowitz SJ, Hunt KK, Kuerer HM, Strom EA, Buchholz TA, Ensor JE, Koutz CA, Robb GL. Practical guidelines for repair of partial mastectomy defects using the breast reduction technique in patients undergoing breast conservation therapy. Plast Reconstr Surg 2007; 120: 1755-68.

18. Currie A, Chong K, Davies GL. Using therapeutic mammoplasty to extend the role of breast conserving surgery in women with larger or ptotic breasts. Ann R Coll Surg Engl 2013; 95: 192-5.

19. Haloua MH, Krekel NM, Winters HA, Rietveld DH, Meijer S, Bloemers FW, van den Tol MP. A systematic review of oncoplastic breast-conserving surgery: current weaknesses and future prospects. Ann Surg 2013; 257: 609-20.

20. Hernanz F, Regaño S, Vega A, Gómez Fleitas M. Reduction mammaplasty: an advantageous option for breast conserving surgery in large-breasted patients. Surg Oncol 2010; 19: e95-e102.

21. Gray JR, McCormick B, Cox L, Yahalom J. Primary breast irradiation in large-breasted or heavy women: analysis of cosmetic outcome. Int J Radiat Oncol Biol Phys 1991; 21: 347-54.

22. Collins ED, Kerrigan CL, Kim M, Lowery JC, Striplin DT, Cunningham $B$, Wilkins EG. The effectiveness of surgical and nonsurgical interventions in relieving the symptoms of macromastia. Plast Reconstr Surg 2002; 109: 1556-66.

23. Khoo A, Kroll SS, Reece GP, Miller MJ, Evans GR, Robb GL, Baldwin BJ, Wang BG, Schusterman MA. A comparison of resource costs of immediate and delayed breast reconstruction. Plast Reconstr Surg 1998; 101: 964-8.

\section{Address for correspondence}

\section{Mustafa Emiroglu}

Department of General Surgery

Tepecik Training and Research Hospital 35010 Izmir, Turkey

e-mail: musemiroglu@gmail.com

Submitted: 8.10 .2014

Accepted: 13.07 .2015 